\title{
"SUA CASINHA É MEU PALÁCIO": POR UMA CONCEPÇÃO DIALÓGICA DE REFERENCIAÇÃ̃O
}

Francisco Alves Filho**

Resumo: Muito se tem falado acerca da inconsistência da noção de referente empírico e da necessidade de se adotar uma concepção processual da referenciação. Contudo, a perspectiva processual apresenta inconsistências por não adotar uma metodologia que analise efetivamente o discurso e por não perceber o caráter dialético envolvendo a instabilidade e a estabilidade referencial. $O$ objetivo deste artigo é discutir as relações entre as noções de dialogismo e referenciação buscando investigar em que medida se pode dizer que a referenciação tem essencialmente uma natureza dialógica. A análise realizada busca correlacionar as escolhas léxico-gramaticais para referir as vozes sociais que as orientam, de modo a se poder explicar efetivamente os objetos de discurso. $O$ estudo indica que a noção de instabilidade referencial pode ser mais bem compreendida se vista em correlação à noção de estabilidade referencial, uma vez que mudanças léxico-gramaticais encontradas nos textos podem indicar tanto instabilidade como estabilidade referencial.

Palavras-chave: dialogismo; referenciação; objeto de discurso; Instabilidade referencial.

\section{INTRODUÇÃO}

O objetivo deste artigo é discutir as relações entre as noções de dialogismo e referenciação buscando investigar em que medida se pode dizer que a referenciação tem essencialmente uma natureza dialógica ${ }^{1} \mathrm{e}$

\footnotetext{
* Este trabalho teve o apoio financeiro da FAPEPI/CNPq (processo $\mathrm{n}^{\circ}$ 20203.0484/2008) e da CAPES (Projeto PROCAD/NF $\mathrm{N}^{\circ}$ 21001014008P0), instituições às quais expresso meu agradecimento.

** Professor da Universidade Federal do Piauí. Doutor em linguística. Email: chicofilhoo@gmail.com.

${ }^{1}$ Seguimos aqui muito de perto a noção de dialogismo formulada por Voloshivov (1976), cujo princípio geral é o de que todo o uso da linguagem ampara-se em índices de valor social e no dizer
} 
quais são as implicações teóricas de uma posição como esta. É uma tentativa de apresentar respostas para indagações do tipo: todo ato de referenciação é de natureza dialógica, ou seja, referir implica necessariamente um diálogo com outras referenciações já realizadas, seja refutando-as, seja concordando com elas? Quando alguém refere, apoia-se necessariamente em referências já produzidas ou poderá produzir referenciacões inusitadas, ad hoc? O que significa efetivamente dizer que a referenciação resulta de um processo de construção colaborativa? Em que medida a natureza e o efeito da referenciação dependem do gênero de discurso no qual ela se insere, ou seja, em que medida o gênero funciona como uma espécie de macrovoz a orientar o ato de referir? Não esperamos oferecer respostas para todas estas instigantes indagações, mas esperamos indicar alguns caminhos no sentido de refinar a noção de referenciação.

\section{DISCUSSÃO}

\subsection{Objetos de mundo versus objetos de discurso}

Os primeiros estudos acerca da referência (não se usava ainda o termo referenciação), embora seu foco fosse o produto e não o processo e ainda que não se formulasse a questão por esta perspectiva, supunham tacitamente que o ato de referir era eminentemente monofônico. Isso pode ser visto em Frege (1978), quando formula que a referência de uma sentença é o seu valor de verdade. Ainda que Frege não mencione quem se responsabiliza por esta verdade, ou seja, não se pergunte a respeito do sujeito ou voz social que orienta ou define o suposto valor de verdade, pode-se inferir que alguma instância deve presidir a determinação de tal suposição. Ou seja, se se imagina que há um valor de verdade, é porque haveria uma voz social que a sustentaria e a defenderia, por ela se responsabilizando. Por estar orientado pelo paradigma epistemológico racionalista e objetivista do final do século XIX, Frege apoia-se na ideia

\footnotetext{
do outro. Isso implica em conceber o enunciado como constitutivamente social e não como individual. O dialogismo ampara-se em duas evidências: a) todo enunciado traz indícios de enunciadores anteriores; b) todo enunciado antecipa-se sobre os enunciados aos quais se destina, tornando o ouvinte uma presença imanente.
}

ALVES FILHO - "Sua casinha é meu palácio"... 
tácita de que a referência tem um caráter monofônico. Havendo referência (e somente haverá, para ele, quando houver um valor de verdade), ela se sustenta na única voz que a legitima. Assim pautada por critérios empiristas, a verdade referencial seria determinada pela voz da ciência daquela época. Aos olhos de hoje, parece um tanto ingênuo imaginar que somente haja uma verdade para cada referência e que esta verdade emane de um único ponto de vista, uma vez que muitas ciências, mesmo aquelas chamadas um tanto equivocadamente de exatas, já admitem a relatividade dos fatos e das ideias sobre estes.

Frege tem sido muito criticado pelos estudiosos modernos da referenciação (MONDADA; DUBOIS, 2003 e MARCUSCHI, 2005) por ter adotado uma concepção empirista de referente, embora pareça improvável excluir completamente certo componente de empirismo para grande parte dos referentes. Tanto é assim que mesmo autores que advogam contra a visão empirista referencial de Frege terminam dizendo coisas do tipo: o referente corresponde às coisas do mundo. Parece inevitável proceder a algum tipo de associação entre o referente e as "coisas do mundo", desde que se conceba que existem diversos mundos (imaginário, memorial, hipotético etc), ou seja, desde que não se restrinja o mundo apenas à empiria. Em outras palavras, o referente inevitavelmente diz respeito às realidades extralinguísticas e não deveria ser confundido ou substituído unicamente pelo sentido das palavras. $\mathrm{O}$ problema da visão empirista de Frege para a perspectiva atual é pautarse por um abstracionismo monofônico, na medida em que supõe a existência de uma associação biunívoca entre signo e coisa, pressupondo uma ontologia preexistente.

Uma das perguntas mais salutares para os estudos da referenciação é se indagar como os objetos de discurso recriam os objetos de mundo e como os objetos de mundo influenciam a criação dos objetos de discurso, o que implica lidar com uma noção dialética para este fenômeno. Em linhas gerais, vamos defender aqui que os objetos de discurso refletem e, ao mesmo tempo, refratam os objetos do mundo, o que implica admitir que a construção de objetos de discurso não deve ser vista como um processo apenas discursivo e feito à margem ou a despeito das realidades. Como, convincentemente, defendeu Blikstein (1990), a práxis social exerce influência decisiva sobre o 
componente linguístico do ato de referir, embora admita que seja ela também influenciada pela linguagem.

Por isso, para explicar a referenciação, parece uma boa saída incorporar a noção de realidade fabricada proposta por Blikstein (1990), o que evita uma visão ingênua e empirista de mundo, mas ao mesmo tempo contempla o fato de que o referente precisa dar conta das realidades extralinguísticas, o que inclui os diversos mundos (físico, biológico, das ideias, dos sonhos, das ficções), de tal forma que explicar os referentes dos discursos implica em nos indagarmos como é que as diversas realidades são categorizadas nos discursos e como é que com o discurso se relacionam. Deveria ficar claro que isso não exclui pensar também qual a influência que o mundo empírico exerce sobre os objetos de discurso. Vieira (2010) concluiu que a natureza semântica e ontológica do objeto de discurso interfere na construção referencial realizada em gêneros argumentativos. Em referência a pessoas individuais, há preferência pelo uso do nome próprio, sendo que a apreciação axiológica manifesta na predicação não é homologada em rótulos; em referência a pessoas concebidas coletivamente, o locutor manifesta apreciação axiológica tanto nas expressões referenciais quanto nas predicações, homologando as predicações. Já na referência a eventos, o locutor faz uso mais intenso de itens lexicais rotuladores e avaliadores tanto nas expressões referenciais quanto na predicação.

Embora significado, sentido e referência sejam noções que possuam relações de mútua influência, ainda assim pensamos que se deve preservar uma diferença conceitual entre eles. Bakhtin (1979) faz a diferença entre o significado (o componente semântico que é recorrente, estável, idêntico e potencial em várias ocorrências de uma palavra; aquilo que pode ser dicionarizado) e o tema/sentido (o aspecto semântico que é único, instável e concreto; dificilmente pode ser dicionarizado). Mas Bakhtin esclarece que tanto o significado como o tema são dependentes da apreciação axiológica que fazem os usuários acerca da linguagem e dos fatos do mundo. Do modo como compreendemos, quando os sujeitos constroem o referente ou objeto de discurso apoiam-se tanto no significado quanto no sentido. Ou seja, se é certo que os objetos de discurso não correspondem às próprias coisas empíricas; não é menos certo que eles também não correspondem exatamente ao significado das palavras. Uma vez que a realidade, 
enquanto fenômeno cultural, somente pode ser apreendida via sistemas perceptivo-semióticos (cf. BLIKSTEIN,1990), marcados inevitavelmente por valorações axiológicas (cf. BAKHTIN, 1979 e 2003), instala-se de vez a impossibilidade de os referentes serem inteiramente objetivos, unos e homogêneos, como teorias clássicas caracterizaram.

Contudo, dito de modo assim tão generalizante, esta formulação não explica de modo minimamente apropriado, o que significa dizer que os referentes não são os mesmos e nem sempre idênticos a si mesmos. Alves Filho (2008) discute as aproximações e distanciamentos entre as noções de sentido e referência, com o intuito de mostrar que se trata de duas noções extremamente interdependentes, dado que o sentido que se estabiliza para uma palavra é tributário das referências que ela pode realizar recorrentemente por muito tempo. É esta recorrência estabilizadora que permite fazer com que o sentido possa ser previsto, suposto e demonstrado, independentemente de uma enunciação particular.

Contudo, pensamos que se deveria ainda preservar uma diferença entre os dois e talvez um dos caminhos para fazer isso fosse trabalhar com a noção de tema de Bakhtin (1979). Tal qual o tema, que é único e irrepetível, também a referência somente pode ser apreendida numa situação única e particular. Ou seja, somente é possível falar de referentes quando estamos diante de enunciados concretos e únicos porque somente numa circunstância destas nos indagamos a respeito de qual realidade está sendo mencionada/fabricada. Em termos de sentido dicionarizado numa língua, não é possível delimitar os referentes de uma palavra porque ela pode referir um objeto de mundo cujo sentido não guarda relação semântica com ela. Por exemplo, é possível usar a palavra "bola" para designar uma certa criança, embora "bola" e "criança" não compartilhem traços semânticos.

\subsection{Plurilinguismo referencial}

Voltemos uma vez mais a Frege (1978) porque suas teses não deveriam ser de todo abandonadas. Do nosso ponto de vista, podemos fazer uma espécie de ajuste, ou melhor, de bifurcação plural de uma de suas teses: o valor de verdade como sendo um critério para definir os referentes. Embora não se possa hoje concordar com Frege quanto ao 
fato de que cada expressão tenha apenas como referência um único valor de verdade, dado que a pluralidade de sentidos e de referência é uma evidência óbvia nas práticas de linguagens; e ainda que não se possa concordar com a própria concepção de valor de verdade, dado que pensar em valor aqui implica pensar numa estabilidade estrutural e numa unicidade fixa, não há como negar que é a busca por uma verdade (embora parcial, interessada, ideológica) que guia os processos de interação social pela linguagem. Pensamos que se poderia defender que, não as sentenças, porque estas são unidades formais, mas os enunciados, do modo como foram concebidos por Bakhtin (2003), possuem, sim, índices de verdade, mas desde que se conceba, é claro, que os índices de verdade não são pacíficos, mas motivos de disputa pelos falantes nas diversas situações comunicativas.

Quando alguém refere algo de algum mundo, seu intento é que tal ato de referenciação seja aceito como verdadeiro ou como válido ou como bom pelos seus interlocutores: o empreendimento enunciativo é orientado com base na busca de uma verdade referencial. É bastante provável que nossos interlocutores recusem parcialmente ou inteiramente o nosso índice de verdade. Pois é justamente nesta contrapalavra que teremos a manifestação do que estamos chamando de plurilinguismo referencial, ou seja, do fato de que sobre um dado objeto referenciável coexistem diversos modos de referi-lo e que estes modos vêm carregados inevitavelmente de valoração axiológica. Ou seja, é o querer ser verdadeiro que engatilha o plurilinguismo referencial.

Entretanto, há que se ter certo cuidado com esta afirmação porque, dependendo do ponto de vista que se adota para observá-la, ela pode significar uma ou outra coisa. Ou seja, a ideia de um plurilinguismo referencial muda de figura se é vista pelo ponto de vista de um único sujeito ou se pelo prisma da alternância de sujeitos ou da interação entre falantes. Dito de outro modo, em relação a grupos sociais distintos, não há como definir um único índice de verdade referencial, mas do ponto de vista de um único indivíduo ou de uma comunidade discursiva bem coesa, pode-se dizer que a referência para cada indivíduo ou grupo pode equivaler a um índice de verdade (embora provisório) que é comum e cultivado entre eles e que corresponde àquele os quais eles habitualmente defendem. Se, por exemplo, um docente do sindicado dos professores refere à UFPI como curral eleitoral é porque, para este 
fulano, é verdadeira a associação entre a expressão referencial curral eleitoral e esta instituição, sendo que tanto ele poderá mencionar esse mesmo referente com outras expressões referenciais pautadas pelo mesmo índice de verdade, como outros colegas de sindicato também poderão fazê-lo. E se, por sua vez, o reitor desta instituição a refere como a maior universidade em expansão do Brasil, é porque é esta a sua (embora diferente) verdade referencial. Do nosso ponto de vista, é justamente a presunção de um valor de verdade, ideológico, repetimos, que está na base daquilo que Mondada e Dubois (2003) chamam de instabilidade referencial.

Se existe plurilinguismo referencial, como estamos aqui a defender, é porque, pelo menos por um lado, a referenciação é um processo largamente instável, conforme formalizara Mondada e Dubois (2003). Na lógica destas autoras, a referenciação é constitutivamente instável, de tal sorte que é comum nas práticas de linguagem a falta de concordância ou coincidência entre os modos como diferentes falantes referem os mesmos objetos de mundo. De fato, e nisso as autoras têm inteira razão, existe uma instabilidade categorial, fruto de processos de discordância e de negociação entre os falantes a respeito de qual forma thes parece mais adequada para referir os objetos de discurso.

O ponto de interesse do argumento de Mondada e Dubois é o fato de explicar, com certo detalhamento, a inexistência de uma relação biunívoca e estável entre a linguagem e os referentes. Focando-nos num dos pontos da tese da instabilidade referencial, queremos defender aqui que a referenciação pode ser vista como dialógica pelo fato de que os falantes não agem, no processo referencial, de modo inteiramente individual. Embora possam usar uma expressão referencial um tanto imprevista num dado discurso, ainda assim o processo de referenciação é marcadamente socioideológico. Ou seja, os indivíduos não referem sozinhos, porque fabricam os referentes segundo "óculos sociais", para usar aqui expressão de Blikstein (1990), mesmo quando dão a entender que o fazem de modo individual.

Embora possa parecer à primeira vista, usar expressões diferentes para referir as mesmas realidades extralinguísticas não significa automaticamente que os referentes são substancialmente diferentes. Ainda num caso como este, o objeto de discurso pode ser o mesmo, já que expressões referenciais diferentes do ponto de vista léxico- 
semântico podem se mostrar bastante congruentes do ponto de vista da apreciação axiológica, podendo, portanto, contribuir para a construção de um mesmo referente ou um mesmo objeto de discurso. Definir com alguma exatidão o que permite dizer que estamos ou não diante de um mesmo objeto de discurso é algo bastante complexo e de difícil explicação. Diríamos que simplesmente mudar a expressão referencial não significa mudar o objeto de discurso; ademais, faz-se necessário observar também a predicação apresentada para cada referente, uma vez que, como já demonstrou Apothéloz (1995), nem sempre a expressão referencial acompanha as mudanças indicadas pela predicação, como é o caso aludido por ele quando a predicação apresenta transformações no referente, as quais não são homologadas pela expressão referencial. Em linhas gerais, diríamos que decidir pela existência de um objeto de discurso implica em observar o tipo de apreciação axiológica que sobre ele incide e qual voz social o enuncia - afinal, estas são condições para a constituição de discursos e de, é claro, objetos de discurso.

Seguindo em parte a tese da instabilidade/estabilidade referencial de Mondada e Dubois (2003), pensamos que não se deveria exagerar o aspecto da instabilidade categorial, perdendo de vista o caráter dialético da referenciação quanto à instabilidade/estabilidade. A estabilidade categorial não precisa ser vista como um processo que trabalha à parte, como se sua função fosse calar ou impedir a instabilidade, já que instabilidade e estabilidade referencial podem coexistir no discurso de um mesmo sujeito ou num mesmo texto. Dito de outra forma, instabilidade e estabilidade categorial são processos concomitantes e disputantes, de modo que, se existe instabilidade referencial numa dada interação, ela pode perfeitamente ser o resultado de uma estabilidade anterior, como, de resto, defendem as autoras.

Vejamos como isso ocorre num exemplo de interação cotidiana. Trata-se do recorte de uma conversação cotidiana ocorrida na cozinha de uma casa de classe média na cidade de Pedro II (PI-Brasil), no dia 9 de junho de 2007. Numa situação de conversa informal, enquanto os membros da família estavam sentados à mesa para fazer um lanche, chegou A, uma ex-empregada doméstica da casa. A é de classe baixa, frequentadora assídua de uma igreja evangélica, trabalhou durante muito tempo nesta casa e criou laços de amizade com os donos da casa. B, 
filho do dono da casa, é professor universitário, conviveu muito com A, com quem gosta muito de conversar.

\section{Exemplo}

B: A senhora ainda está morando na mesma casinha?

A: Continuo lá no meu palácio.

No exemplo 1, pode-se dizer que, entre o modo de referir realizado por B e o realizado por A, há uma instabilidade categorial, um desacordo, pois um mesmo objeto de mundo (certa casa real, conhecida dos dois falantes) é alçado à condição de objeto de discurso diferente (casinha para um e palácio para outro; vista negativamente por um e positivamente por outro). Tal instabilidade categorial torna-se mais visível quando vista do exterior, por um terceiro, enquanto, do ponto de vista de cada um dos falantes envolvidos, que provavelmente é também o ponto de vista de seu grupo socioideológico, este modo de referir é bastante estável, a ponto de A se recusar a chamar o lugar onde mora de casinha. Para A (mas não somente para ela), sua casa é um palácio e pronto. Entretanto, há que se levar em conta a grande probabilidade de que o objeto de discurso palácio - assim formulado - se faça presente em muitos de seus enunciados e de enunciados de pessoas do mesmo grupo socioideológico ao qual ela se vincula. E, de fato, referir qualquer casa, mesmo uma extremamente pobre e em péssimas condições físicas, como "palácio", é um ato altamente estável realizado recorrentemente por certos pastores e seguidores de certas igrejas. É que essa escolha referencial está a serviço de/e materializa um discurso que prega a resignação material e a aceitação de qualquer dificuldade como uma dádiva de Deus e como uma condição para uma felicidade futura. De fato, não é $\mathrm{A}$, rigorosamente falando, a responsável pelo objeto de discurso palácio. Para quem segue os mesmos princípios religiosos de A, será altamente estável referir casas em precárias condições físicas como palácios.

O que estamos pretendendo dizer é que, em algum grau, um objeto de discurso já preexiste, sendo-lhe impossível ser inusitado ou original - o objeto de discurso palácio não foi construído nesta conversação. E isso se dá por duas razões: primeiro, porque as expressões escolhidas para referir, inteira ou parcialmente já foram usadas em referências anteriores - numa concepção dialógica de 
linguagem, não há referência original, embora o ato de referir seja único e irrepetível; segundo, porque a forma como sociocognitivamente percebemos e apreendemos as realidades nunca é inteiramente individual. Referir é apropriar-se de modos de referir relativamente estabilizados no seio dos grupos sociais, o que justifica dizer que a referenciação precisa ser pensada também como um ato de apropriação de modos de referir preexistentes no universo social. De fato, embora em cada interação real o processo de referenciação possa, algumas vezes, tomar um rumo diferente, resultando numa configuração lexical e semântica num certo sentido única, isso não justifica pensar que o processo de referenciação é inteiramente elaborado no ato pragmático em si.

Do nosso ponto de vista, o ato pragmático único e inédito de construção de um processo referencial se ampara sociocognitivamente em conjuntos de índices sociais de valores dados e relativamente estabilizados. Em suma, cada referenciação é ao mesmo tempo nova e dada. Nova como configuração léxico-semântico particular, como realização particular num enunciado único e irrepetível, mas dada como decorrente diretamente de algum discurso social e como expressão de uma apreciação axiológica legitimada socialmente. (Como dissemos acima, a construção do referente se apoia tanto no significado como no tema/sentido). Diríamos, seguindo a tese dialógica de Bakhtin, que quem refere não é o eu, mas o nós.

Grupos sociais diferentes referem de modos diferentes uma dada realidade e tentam, cada grupo, impor ou, talvez menos, orientar o seu modo de referir como sendo o mais verdadeiro, o mais correto, o mais justo, o mais adequado, o mais pertinente. Observa-se intuitivamente que, nas práticas cotidianas de interação, há uma tendência muito recorrente de uma mesma pessoa ou um mesmo grupo social manter uma relação biunívoca entre signos e referentes já que isso pode garantir certo conforto e segurança psicossocial e comunicacional. Por exemplo, há cidades em que todos tendem a usar a expressão "ponto" para referir o local onde param os onibus coletivos para embarque de passageiros, ao passo que em outras a tendência recai na expressão "parada". Dito de outra forma ainda, o pluriliguismo referencial, evidenciado quando se comparam os modos como grupos sociais diferentes referem suas realidades, tem como contraparte uma aparente monofonia referencial 
do ponto de vista de cada falante ou de um grupo coeso de falantes. Como já mencionado antes, um mesmo ato de referenciação pode ser visto como estável ou instável, a depender do ponto de vista adotado para observar o fato. Por esta razão é que defendemos aqui a necessidade de encarar a referenciação como um processo dialético envolvendo tanto estabilização como a instabilizacão dos processos referenciais. Do ponto de vista de cada um, a referenciação é grandemente estável, embora a um olhar externo que observe as interações entre os sujeitos, a instabilidade referencial possa ser o dado mais saliente.

\subsection{Referenciação e gêneros do discurso}

Outro aspecto importante a considerar nesta discussão sobre dialogismo e referenciação é a relação entre referenciação e gêneros do discurso $^{2}$. Do nosso ponto de vista, o caráter dialógico da referenciação pode ser mais bem compreendido se visto em enunciados concretos, observando-se o seu pertencimento a gêneros. No entanto, no campo da referenciação ainda é muito comum análises arrolarem uma série de exemplos oriundos de fontes diversas, de diversos gêneros, de disparatadas esferas de comunicação, desprezando-se, dentro outros aspectos, a autoria e o coro de enunciadores neles presentes. Isso pode ser visto, dentre outros, em Apothéloz (2003), Ilari (2001), Koch (2001 e 2005) e Marcuschi (2005).

Ao optar por esta metodologia, as análises ignoram algo extremamente importante: que os próprios gêneros do discurso como ferramentas sociocomunicativas, promovem uma relativa estabilidade das estratégias de referenciação. Isto é, os gêneros do discurso "orientam" a atividade referencial dos falantes, fazendo com que os modos de referir se ajustem a determinadas funções "discursivas", o que equivale a dizer que as escolhas léxico-gramaticais para promover os processos de referenciação decorrem, em algum grau, do estilo do gênero, o qual, por sua vez, atende aos propósitos comunicativos

\footnotetext{
${ }^{2}$ Bakhtin estabelece, neste texto de 1929-1930, as distinções entre significação e tema, dizendo que a significação responde pelo significado dicionarizado, previsível, recorrente e abstrato de uma palavra, ao passo que o tema responde pelo sentido único e irrepetível de cada enunciação. Bakhtin não menciona o termo referente ou referenciação, mas é possível dizer que o referente aproxima-se da noção de tema pelo seu caráter de irrepetibilidade. Ou seja, somente a cada ato de enunciação é que se pode dizer qual o referente está sendo mencionado/fabricado.
} 
tipificados em tal gênero. Por exemplo, em gêneros como tutoriais e bula de remédio, a atividade referencial tende largamente para a monofonia e para uma objetividade que busca, com o máximo de eficiência possível, fazer com que cada expressão referencial nominal única seja compreendida como categorizando um mesmo referente. Aqui há uma acentuada tendência para se apagar possíveis polêmicas e os objetos de discurso serem elaborados monofonicamente. Já em editorais de jornal e crônicas, por exemplo, o que prevalece é o plurilinguismo referencial porque se trata de gêneros polêmicos e argumentativos, os quais discutem temas de esferas ideológicas constituídas e precisam lidar com a diversidade de pontos de vista. Um trabalho que realiza uma análise muito pertinente da relação entre referenciação e gêneros é o artigo de Zamponi (2005), no qual a autora investiga os processos de referenciação no gênero "popularização da ciência", o qual é caracterizado pela autora não em termos estruturais, mas pela presença de uma relação assimétrica entre, "de um lado, aquele que sabe, e, de outro, aquele que não sabe" (p. 172). Na análise, a autora mostra que os processos de reformulação são decorrentes do tipo de específico de interação estabelecida, no gênero popularização da ciência, entre especialistas e não-especialistas.

Por esta razão é que um dos problemas de estudos de referenciação que tendem a radicalizar a tese de que os objetos de discurso são sempre criados in loco, pragmaticamente, é generalizar um dos funcionamentos da referenciação como sendo a regra geral. Não se pode negar que, em alguns gêneros e em alguns usos particulares da linguagem, as pessoas objetivam referir de modo tão biunívoco quanto possível naquela circunstância. Em suma, referir é uma ação social e não um ato individual, sendo o seu caráter social coorientado pelos gêneros de discurso. Por estas razões, não é um bom argumento para combater a tradicional noção vericondicional unívoca de referência supor que a referenciação é sempre um processo em aberto a ser resolvido sempre aqui e agora por um eu e um $t u$, os quais construirão inusitados objetos de discurso.

\subsection{Referência de outrem}

Há ainda outro aspecto desta questão, o qual precisa ser discutido num estudo como este: trata-se das formas de introdução do discurso de ALVES FILHO - "Sua casinha é meu palácio"... 
outrem, tão bem demonstradas por Bakhtin (1998 [1975]), as quais, a nosso ver, precisam ser tomadas como incluindo também formas de introdução da referência de outrem no meu discurso. Ou seja, o jogo que atesta o dialogismo da referenciação possui vários graus de demonstração de quem se responsabiliza pela referência. Embora a referência seja constitutivamente dialógica, pelo fato de que ela emerge como reação-resposta a outra referência, ela pode vir marcada de diversos modos nos enunciados, indicando diferentes graus de responsabilização. Teríamos três grandes casos paradigmáticos, seguindo de perto a teoria dialógica de Bakhtin e aplicando-a para o estudo da referenciação.

No primeiro caso, o locutor menciona a fonte da referenciação, ao dizer, por exemplo, segundo fulano, de acordo com sicrano. Ao fazer isso, o locutor alude abertamente o responsável pela referenciação e, ao mesmo tempo, pode se eximir desta responsabilidade. No segundo caso, ele diz para mim, eu acho que, eu penso que e toma para si a responsabilidade pelo ato de referir. O terceiro grande caso dá conta de toda uma série de outras formas menos óbvias em que não há demarcação nítida entre a referência de outrem e a referência do eu, e são justamente estes casos que mais podem dizer interesse ao pesquisador. Sendo formas híbridas ou refratadas, elas exigem do estudioso um trabalho de descoberta e de inferenciação e podem servir a funções retóricas muito particulares, algumas delas sub-reptícias.

Vejamos no editorial seguinte alguns indícios de como funciona a distribuição das vozes sociais responsáveis ou responsabilizadas pelos processos de referenciação. Trata-se de um editorial publicado pelo Jornal Brasileiro Folha de S. Paulo, um dos mais bem conceituados no Brasil, embora seja acusado por seus leitores de ser partidário, o que contrariaria a linha editorial explicitada pelo Jornal, a qual professa independência de grupos políticos. O editorial aqui em foco tematiza a forma como o Governo do Estado de São Paulo possibilita ou distribui a ocupação dos cargos de diretores de ensino na Rede Estadual. Devemos levar em conta que o editorial é um gênero de discurso cujos propósitos retóricos incluem: apreciar negativamente as ações das esferas de poder constituído; promover a imagem da empresa jornalística diante dos seus leitores; aliar-se ou contrapor-se a discursos e ideologias. Por conta desta 
retórica, é de se esperar que num editorial haja modos distintos e opostos de construir os referentes.

\section{Educação loteada}

Não surpreende a informação, divulgada ontem nesta Folha, de que está em pleno vigor o loteamento político nas diretorias de ensino da Secretaria da Educação do Estado de São Paulo. Entre as 91 unidades existentes, o apadrinhamento ocorre em pelo menos 40 .

Os diretores exercem função tipicamente gerencial. São os responsáveis por aplicar os projetos da secretaria, avaliar as escolas e encaminhar demandas como reformas prediais e contratações. O compadrio, contudo, submete à lógica paroquial decisões que deveriam pautar-se pela racionalidade administrativa e pela competência.

A secretaria estadual confirma a indicação política, mas diz que submete os nomes a uma avaliação técnica e exige requisitos mínimos, como o de ser profissional da rede há dez anos. São cuidados meramente paliativos, que douram a pílula da penetração disseminada do clientelismo numa função importante para o funcionamento da rede escolar.

O esquema de loteamento político é antigo no Estado, mas havia sido abandonado no governo Mário Covas (1995-2001) e substituído por um sistema de provas e entrevistas. Voltou a funcionar sob Geraldo Alckmim (PSDB) e continua a vigorar na gestão de seu correligionário José Serra.

Não é alentador o fato de o governo, agora, dispor-se a aplicar prova de proficiência nos atuais dirigentes, encaminhando profissionais com nota baixa para um curso de reciclagem. A escolha de gerentes em todos os setores da administração quanto mais num segmento prioritário, como o ensino - deveria seguir os procedimentos universais para aferir mérito, como concursos.

São Paulo, que continua a lotear postos nas diretorias de ensino, é o mesmo Estado cujos alunos colhem péssimos resultados nos testes de desempenho. Não há de ser mera coincidência. (FSP, 22-08-2008, p. A2). 
Apressadamente talvez se pudesse dizer que há no editorial acima uma extensa instabilidade referencial pelo fato de haver aí variadas expressões categoriais para referir um mesmo evento do mundo político e administrativo (as diversas formas linguísticas presentes no texto, todas negritadas, para mencionar 'o modo como são indicados os diretores das escolas públicas no Estado de São Paulo'). Contudo, se se faz uma análise do editorial por uma perspectiva sócio-histórica, pode-se dizer que há uma grande estabilidade referencial que orienta seus dois grandes conjuntos de cadeias referenciais. O quadro 1 aponta estas correlações.

\begin{tabular}{|l|l|l|}
\hline Expressões referenciais & $\begin{array}{l}\text { Voz social que } \\
\text { orienta a construção } \\
\text { referencial }\end{array}$ & Modo de apreciação \\
\hline $\begin{array}{l}\text { o loteamento político, o } \\
\text { apadrinhamento, o } \\
\text { compadrio, a penetração } \\
\text { disseminada do } \\
\text { clientelismo, o esquema } \\
\text { de loteamento político, } \\
\text { lotear postos nas nas de S. Paulo) } \\
\text { diretorias de ensino }\end{array}$ & Negativo \\
\hline a indicação política & Governo (São Paulo) & \\
\hline
\end{tabular}

Quadro 1 - Voz social e modos de apreciação de expressões referenciais.

Como ilustra o quadro 1 , as expressões referenciais usadas no editorial Educação loteada são orientadas claramente por duas vozes sociais, aqui antagônicas: a da imprensa (Folha de S. Paulo) e a do Governo de São Paulo. Em função de, neste caso, o jornal assumir um ponto de vista contrário ao ponto de vista do governo, as expressões referenciais orientadas pelo prisma do jornal (o loteamento político, o

\footnotetext{
${ }^{3}$ Aqui aparece um dado empírico interessante que é a presença de uma anáfora, cujo anaforizador é a predicação lotear postos nas diretorias de ensino e não uma expressão nominal ou pronominal. Isso é relevante porque há necessidade de rever o pressuposto, tácito em muitos trabalhos, de que a referência ocorre somente com expressões nominais na função sintática sujeito. Este é um inequívoco caso em que o referente loteamento político está sendo correferido com um sintagma verbal.
} 
apadrinhamento, o compadrio, a penetração disseminada do clientelismo, o esquema de loteamento político, lotear postos nas diretorias de ensino) são extremamente coerentes entre si e, em conjunto, colaboram para a construção de um mesmo e único objeto de discurso, o qual é referido por várias descrições definidas; entretanto, vistas em conjunto, e situadas numa cadeia discursiva única, elas são bem diferentes da única expressão referencial guiada pela perspectiva do governo do Estado de São Paulo (a indicação política). Note-se bem que a única ocorrência de uma expressão referencial não alinhada com a apreciação axiológica do jornal ocorre num trecho de discurso indireto, em que o editorial relata o ponto de vista da Secretaria Estadual de Educação (A secretaria estadual confirma a indicação política, mas diz que submete os nomes a uma avaliação técnica e exige requisitos mínimos, como o de ser profissional da rede há dez anos). Este é um indício - importantíssimo para a tese aqui defendida - de que a referenciação possui certo grau de dependência enunciativa em relação à polifonia. Isso posto, fica evidente que, do ponto de vista de cada posição enunciativa envolvida, há uma necessária e funcional estabilidade referencial. Para se dizer que existe aí uma instabilidade referencial, ter-se-ia que ignorar a clara diferenciação polifônica que orienta as opções referenciais. Em suma, usos como estes constituem muito mais casos de plurilinguismo referencial do que propriamente de instabilidade referencial.

Vejamos mais um exemplo em que é possível discutir a construção referencial em editorais. No editorial abaixo, há um conjunto de expressões referenciais cujo objetivo é designar um homem que cometeu um assassinato, o qual ocorreu na cidade de Teresina, em julho de 2007. Como a pessoa assassinada era uma jovem de classe média, o fato teve grande repercussão e foi tematizado fartamente na imprensa local.

\section{SATÃ À ESPERA}

Chegou ao fim mais uma novela policialesca que intrigou a população piauiense. Kleiton Topete, acusado de assassinar a jovem advogada Lílian Samara, há 19 dias, após uma tentativa de assalto na zona Norte de Teresina, enfim, atrás das grades. Mas isso todo mundo já sabe e, claro, é geral o alívio por mais um malfeitor ficar de fora do convívio social. O que surpreendeu, na 
verdade, foram às reações do bandido. Topete disse, primeiramente, em depoimento às autoridades, que não fora ele quem disparara o tiro fatal contra a advogada. Até aí, tudo bem. Era mesmo de se esperar que o facínora colocasse no parceiro a culpa pela morte hedionda da pobre moça. Mas o cinismo e a frieza do delinquente ainda estavam por vir. Cleiton (sic), algemado, vigiado, levado às barras da lei, se humilhou como todo covarde. Disse sentir muito pela própria mãe e pelo próprio pai, que estavam sofrendo com toda aquela situação de perseguição policial e de suspense pela prisão de sua pessoa. Corrigiu alguns números expostos na imprensa e disse que não eram 16 os crimes pelos quais ele estava sendo processado. "Foram só sete", retificou o marginal. Mais (sic) a maior desfaçatez o Topete guardou para o final. Denunciou aos policiais presentes ao seu interrogatório o fato de ter uma seita satânica pronta para matá-lo quando ele fosse recolhido na prisão. Ora, pois. Por quanta aflição passou e tem passado a família da advogada Lílian, morta gratuitamente pela ação deste monstro social? Que diferença faz diminuir uma conta de processos, de 16 para sete, já que o que fica comprovado é a índole do marginal em cometer crimes por cima de crimes sem o menor receio? E, ao final, que medo é esse de morrer pelas mãos dos discípulos de satã, já que Topete patrocina mortes e, por assim ser, tem o inferno como destino fatal? O matador, na verdade, está usando do seu "jus espeniandi" (direito de espernear). Mas não adianta choro e, principalmente no caso dele, dispensa-se qualquer reza. Toda valentia de Topete - que na verdade não passa de mera perversidade - poderá ser usada agora pelos companheiros de cela, afeitos à violência e com plena capacidade de se defender. Isso, para um covarde, pode parecer com o inferno. Daí ele dizer que os filhos de satã o esperam na prisão. Mas essa turma se entende. (Jornal O Dia, 26/07/07).

No editorial acima, há variadas expressões referenciais cuja finalidade é designar um mesmo referente do mundo social. Elas podem, tal qual no texto Educação loteada (aqui analisado), ser agrupadas conforme o discurso a que se vinculam. As descrições definidas com nomes próprios (Kleiton Topete, Cleiton e Topete) e a descrição definida (o matador), por não conterem índices avaliativos, são formas referenciais não marcadas quanto à apreciação axiológica - talvez possam ser lidas como vinculadas ao discurso jornalístico noticioso que 
evita opinar abertamente e que tem como meta aproximar-se de uma observação com algum grau de isenção. Já as expressões um malfeitor, $o$ bandido, o facinora, o delinquente, o marginal e um covarde contêm claros índices avaliativos e, por isso, podem ser tomadas como expressões constituintes de um mesmo objeto de discurso, o qual decorre de um discurso que enxerga o contraventor como um sujeito com defeito moral e/ou social e que, portanto, deve ser punido severamente. $\mathrm{O}$ objeto de discurso assim construído guarda relações diretas com o discurso que se mostra favorável à pena de morte. Para além de apenas referir, estas expressões contribuem para perpetuar um ponto de vista sobre sujeitos que praticam atos como os descritos no editorial.

\section{CONSIDERAÇÕES FINAIS}

Os estudos acerca da construção referencial podem avançar muito se levarem em conta, sobretudo nas análises, o papel desempenhado pelo dialogismo e pelos gêneros do discurso. A instabilidade categorial da referência manifesta-se, sobretudo, quando se observam/contrastam discursos ou vozes sociais diferentes, mas, quando se olha a referenciação do ponto de vista de uma mesma voz ou de um mesmo discurso, vê-se aí uma forte tendência para uma estabilidade referencial. Esse fato deve servir para evitar certo maniqueísmo ao se comparar a instabilidade com a estabilidade. Defender a instabilidade como sendo o processo mais recorrente (ou mais determinante ou mais adequado) não contribui para explicar como efetivamente funciona a referenciação, pelo fato de que se trata de um processo extremamente complexo. Não se trata de dizer que o poder de referenciar é certo ou incerto, adequado ou não adequado. Parece-nos mais justo defender que o poder da língua para referir é funcional e atende aos propósitos dos falantes nas atividades comunicativas. Reafirmamos que a problemática da referenciação é muito complexa e grandemente mal-compreendida porque há problemas quanto ao recorte de dados fragmentados que camufla o seu funcionamento total. Há necessidade de rever a dialética que envolve os processos de estabilidade e instabilidade referencial e proceder a análises que situem os dados não só pragmaticamente, mas 
também dialogicamente, vendo o jogo de interesses e os pontos de vista que guiam as escolhas referenciais.

\section{REFERÊNCIAS}

ALVES FILHO, F. Sentido e referência: um caso de discretização ou de continuidade? In: ; LIMA, M. A. F; FERNANDES, M. do S. C. (Orgs.).

Olhos espraiados: literatura e linguagem ao sol. Recife: Bagaço, 2008, p. 2835 .

APOTHÉLOZ, D. Papel e funcionamento da anáfora na dinâmica textual. In: CAVALCANTE, M. M.; RODRIGUES, B. B.; CIULLA, A. (Orgs.).

Referenciação. São Paulo: Contexto, 2003, p. 52-84.

APOTHÉLOZ, Denis ; REICHLER-BÉGUELIN, Marie-José. Construcion de la référence et stratégies de designation. BERRENDONNER, A.; REICHLERBÉGUELIN, M.J. (Orgs.). Du sintagme nominal aux objets-de-discours: SN complexes, nominalisations, anaphors. Institute de Linguistique. Université de Neuchâtel: Suisse. Travaux Neuchatelois de Linguistique (TRANEL), n. 23, p. 227-271. 1995.

BAKHTIN, M. Tema e significação na língua. In: . Marxismo e filosofia da linguagem. São Paulo: AnnaBlume/Hucitec, 1979, p. 128-136.

. Os gêneros do discurso. In: São Paulo: Martins Fontes: 2003. p. 261-306. . Estética da criação verbal. 4. ed. .Questão de literatura e de estética: a teoria do romance. São Paulo: Ed. Unesp/Hucitec, 1998.

BLIKSTEIN, I. Kasper Hauser ou a fabricação da realidade. São Paulo: Cultrix, 1990.

FREGE, Gottlob. Sobre o Sentido e a Referência. In: da linguagem. São Paulo: Cultrix/Edusp, 1978 p. 61- $\overline{86 .}$ . Lógica e filosofia

ILARI, R. Anáfora e correferência: por que as duas noções não se identificam? Caderno de estudos linguísticos, Campinas, (41), p. 91-109 Jul./Dez. 2001. KOCH, I. V. Desvendando os segredos do texto. São Paulo: Cortez, 2001. . Referenciação e orientação argumentativa. In: KOCH, I. V; MORATO, E. M.; BENTES, A. C. (orgs.). Referenciação e discurso. São Paulo: Contexto, 2005. p. 33-52. 
MARCUSCHI, L. A. Anáfora indireta: o barco textual e suas âncoras. In: KOCH, I. V; MORATO, E. M.; BENTES, A. C. Referenciação e discurso. São Paulo: Contexto, 2005.

MONDADA, L.; DUBOIS, D. Construção dos objetos de discurso e categorização: uma abordagem dos processos de referenciação. In: CAVAlCANTE, M. M., RODRIGUES, B. B., CIULlA, A. (Orgs.). Referenciação. São Paulo: Contexto, 2003, p. 17-52.

PORTELA, E. M. S. Tema: uma abordagem socioaxiológica em editoriais de jornais piauienses. Dissertação (Mestrado em Letras) - Centro de Ciências Humanas e Letras, Universidade Federal do Piauí, Teresina, 2008.

VIERA, L. M. Construção de objetos de discurso em cadeias textuais: a inter-relação entre expressão referencial e predicação. Dissertação (Mestrado em Letras) - Mestrado Acadêmico em Letras, Universidade Federal do Piauí, Teresina, 2010.

VOLOSHIVOV, V. N. Discurso na vida e discurso na arte. Freudism. New York, Academic Press, 1976. (Tradução para o português, para uso didático, de Carlos Alberto Faraco e Cristóvão Tezza - não publicada.)

ZAMPONI, G. Estratégias de construção da referência no gênero de popularização da ciência. In: KOCH, I. V.; MORATO, E. M.; BENTES, A. C. (Orgs.). Referenciação e discurso. São Paulo: Contexto, 2005, p. 169-195.

Recebido em 04/03/09. Aprovado em 05/03/10.

Tile: "Your little house is my palace": towards a dialogic conception of referentiation

Abstract: Much has been discussed about the inconsistency of the empirical referent and the need to use a processual conception of referentiation. However, the processual perspective presents inconsistencies because it does not use a methodology that really analyzes the discourse and does not take into account the dialectical perspective that involves referential stability and instability. This article aims at discussing the relations between the notions of dialogism and referentiation, trying to investigate under which circumstances one can say referentiation has a dialogical nature. The analysis tries to correlate the lexicogrammar choices to refer to the social voices that orient them, so that one can explain the discourse objects. The study indicates that the notion of referential instability can be better understood when one sees it in correlation to referential stability, since the lexicogrammatical changes found in texts can indicate not only referential instability but also referential stability.

Keywords: dialogism; referentiation; discourse object; referential instability. 